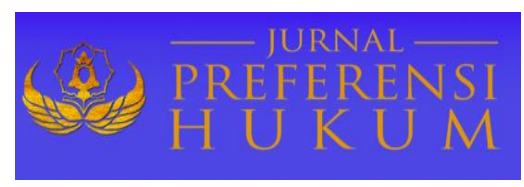

Jurnal Preferensi Hukum | ISSN: XXXX | E-ISSN: XXXX

Vol. 1 No. 1 - Juli 2020 hal. 104-112| Available online at https://www.ejournal.warmadewa.ac.id/index.php/juprehum

\title{
KEDUDUKAN KRAMA BALU LUH DI DESA ADAT SUTER BANGLI
}

\author{
I Made Suriana, I Made Suwitra, Diah Gayatri Sudibya \\ Fakultas Hukum Universitas Warmadewa, Denpasar-Bali, Indonesia
}

\begin{abstract}
Abstrak
Sistem keturunan patrilineal di Bali memberikan konsekuensi pada para ahli waris yang ditentukan menurut garis keturunan laki-laki (purusa). Namun, hal ini tidak tertutup kemungkinan bagi pihak perempuan untuk diangkat menjadi ahli waris, yaitu dalam hal anak perempuan tersebut diangkat menjadi sentana rajeg. Penelitian ini dilakukan untuk mengetahui kewajiban krama balu luh di Desa Adat Suter Bangli dan kewenangan krama balu luh terhadap harta peninggalan suaminya. Tipe penelitian yang digunakan adalah penelitian hukum empiris. Kewajiban krama balu luh di Desa Adat Suter Bangli antara lain mengurus harta peninggalan almarhum suaminya dengan baik, berperilaku baik, menegakkan kedisiplinan, taat melaksanakan kewajiban, melaksanakan upacara panca yadnya dan lain- lain, yang kemudian disebut dengan balu pageh, hak janda tersebut hanya boleh dinikmatinya tidak boleh dijual, digadaikan, dan diberikannya kepada orang lain kecuali atas persetujuan dari anak-anaknya dan keluarga almarhum suaminya jika anak-anaknya masih kecil-kecil. Hal ini berlaku untuk harta pusaka dan harta guna kaya (harta perkawinan), karena untuk harta pusaka, janda tidak punya hak apapun, yang berhak ialah purusa dari keluarga almarhum suaminya, namun janda berhak untuk menikmatinya jika janda tersebut pageh. Kewenangan krama balu luh terhadap harta peninggalan suaminya antara lain memelihara keutuhan keluarga, berbuat hal baik, sehingga dapat disebut balu luh yang pageh. Tidak berwenang menjual, memindahtangankan harta yang ditinggalkan oleh almarhum suaminya. Boleh meminta anak/sentana, tapi atas persetujuan keluarga besar almarhum suami. Juga boleh kawin lagi atas persetujuan keluarga besar almarhum suami.
\end{abstract}

Kata Kunci: Desa adat; Kewajiban; Kewenangan; Krama Balu Luh; Warisan

\begin{abstract}
The patrilineal descent system in Bali has consequences for the heirs who are determined according to the male lineage (purusa). However, it is also possible for women to be appointed as heirs, that is, in the case of girls being appointed as sentana rajeg. This research was conducted to determine the obligations of the manners of Balu Luh in the Suter Bangli Customary Village and the authority of the manners for the inheritance of her husband. The type of research used is empirical legal research. The obligations of the courtesy of Suter Bangli Customary Village include taking care of the inheritance of her deceased husband well, behaving well, upholding discipline, obeying the obligations, carrying out the panca yad ceremonies and others, which are then called balu pageh, the rights of the widow may only be permitted she enjoyed not being able to be sold, pawned, and given to others except with the consent of her children and the family of her late husband if the children were still small. This applies to inheritance and rich use (marriage assets), because for inheritance, the widow does not have any rights, the right is purusa of the family of her deceased husband, but the widow has the right to enjoy it if the widow is pageh. The authority of the manners of the husband for the inheritance of her husband includes maintaining the integrity of the family, doing good things, so that it can be called a shameful pageh. Not authorized to sell, transfer assets left by her late husband. May ask for children/sentana, but with the consent of the family of the late husband. May also remarry with the approval of the family of the late husband.
\end{abstract}

Keywords: Customary village, Obligation, Authority, Krama Balu Luh, Inheritance 


\section{PENDAHULUAN}

Dalam membahas secara mendalam mengenai konsep kedudukan balu luh di Desa Adat di Bali umumnya dan di Desa Adat Suter Kintamani khususnya, tidak bisa lepas dari masyarakat hukum adat sebagai persekutuan hukum desa adat di Bali, seperti yang dijelaskan oleh (Suwitra, 2014)bahwa unsurunsur yang dapat direfleksikan untuk dijadikan ukuran dalam memandang apakah suatu kelompok masyarakat tertentu pantas dianggap sebagai masyarakat hukum adat atau tidak adalah kelompok masyarakat yang berada dalam ikatan tradisi yang sama, mempunyai otonomi (asli) dalam sistem pemerintahaannya, mempunyai harta kekayaan sendiri, baik yang bersifat duniawi maupun yang bersifat magis religious, mempunyai wilayah sendiri dengan batas-batas tertentu.

Keempat unsur tersebut telah dimilik oleh Desa Adat Suter, sehingga Desa Adat Suter layak disebut sebagai masyarakat hukum adat. Sebagaimana kita ketahui bahwa masyarakat Indonesia terdiri dari bermacam-macam budaya, suku ataupun ras, agama dan kepercayaan sehingga menimbulkan adanya perbedaan khususnya dalam bentuk kekeluargaan dengan sistem keturunan yang berbeda-beda pula. Sistem keturunan yang berbeda-beda ini berpengaruh terhadap sistem pewarisan hukum adat.

Sistem kekeluargaan dapat dibedakan menjadi tiga bentuk, yaitu sistem patrilinial (Hadikusum, 2003; Yusa, 2017) yaitu sistem kekerabatan yang ditarik menurut garis keturunan ayah dan dalam hal pewarisan laki-laki lebih diutamakan, sistem matrilinial yaitu sistem kekerabatan wanita yang ditarik menurut garis keturunan ibu dan dalam hal pewarisan wanita yang lebih diutamakan, dan sistem parental/bilateral yaitu sistem kekerabatan yang ditarik menurut garis keturunan ayah atau garis keturunan ibu dan dalam hal pewaris antara pria dan wanita adalah sama atau tidak dibeda-bedakan. Kendati masyarakat Bali menganut system patrilineal, akan tetapi dalam perspektif hukum waris kedudukan ahli waris perempuan Bali merupakan ahli waris yang sah kedudukannya, dan dapat dipersamakan dengan lakilaki sebagai ahli waris (Harum \& Kusuma, 2013).

Masyarakat Bali sistem kekeluargaan yang digunakan adalah sistem kekeluargaan patrilinial. Cara pengelompokan kekeluargaan yang berdasarkan atas garis purusa tersebut dijiwai oleh hukum kekeluargaan umat Hindu di Bali yang dalam kehidupan sehari-hari telah menyatu dengan hukum adat.

Di dalam kehidupan manusia banyak mengalami peristiwa-peristiwa penting yang secara kodrat harus dihadapinya. Peristiwa-peristiwa tersebut antara lain kelahiran, perkawinan, kematian serta kewarisan. Peristiwa mana akan menimbulkan akibat-akibat hukum, baik secara hukum keperdataan maupun secara adat. Semenjak manusia lahir, maka secara etik kemanusiaan ia telah dibebani dengan kewajiban yaitu berbakti kepada orang tua.

Masyarakat Adat di Bali menganut garis keturunan kepurusa, sistem yang demikian membawa konsekuensi bahwa yang berhak mewarisi adalah anak laki-laki, karena anak laki-lakilah yang dianggap sebagai penerus keturunan keluarga. Sistem ini secara adat tidaklah mempunyai nilai kemasyarakatan belaka, tetapi juga mempunyai nilai niskala, sekala, religi dan sosial.

Hal ini sesuai dengan falsafah Tri Hita Karana, yaitu harmonisasi hubungan antara manusia dengan manusia, manusia dengan alam, dan hubungan dengan Tuhan. Demikian pentingnya seorang anak khususnya anak laki-laki dalam suatu keluarga, sehingga timbullah kesan seolah-olah anak perempuan tidak mendapat tempat di dalam keluarga. Apalagi anak perempuan yang kawin keluar, sehingga pada umumnya menurut hukum adat Bali putuslah hubungan keperdataan dengan keluarganya semula, yang berarti anak wanita tidak lagi menjadi ahli waris orang tuanya.

Kalau dilihat sampai sekarang adanya perkembangan masyarakat di berbagai bidang, perkembangan tersebut juga menyangkut berbagai nilai-nilai yang hidup dalam masyarakat serta perasaan hukumnya. Emansipasi merupakan tuntutan kesamaan hak antara wanita dengan pria, seolah-olah semakin nampak dalam perkembangan dewasa ini. Namun dapatlah kiranya perkembangan yang berupa emansipasi diterapkan dalam aspek hukum khususnya hukum adat Bali.

Berbicara mengenai hukum adat khususnya hukum adat waris, maka terbayang dalam ingatan yaitu adanya peralihan harta kekayaan baik secara materiil maupun immaterial dari satu generasi ke generasi berikutnya, Pewarisan menurut hukum adat Bali adalah proses penerusan atau pengoperan kewajiban dan hak dari suatu generasi ke generasi berikutnya. 
Konsep pemikiran ini menimbulkan kesan bahwa sepanjang seseorang masih memikul kewajiban, maka orang tersebut masih mempunyai hak untuk menjadi ahli waris, tidak terkecuali baik anak perempuan maupun anak laki-laki. Karena membicarakan hukum adat waris khususnya di Bali tidak bisa dilepaskan dari kewajiban dan hak para ahli waris. Dalam sistem kewarisan di Bali dikenal 3 sistem, yaitu kewarisan Individual, Kewarisan kolektif dan Kewarisan Mayorat, yang disana-sini disertai dengan variasi sesuai dengan desa kala patra (Sutha, 1982).

Hukum adat waris di Bali masih beragam sifatnya, dalam arti kewarisan di satu desa adat tertentu belum tentu sama dengan kewarisan di desa adat lainnya. Dengan dianutnya system kebapaan (patrilineal) di Bali, maka yang menonjol adalah anak laki-laki. Anak laki-laki akan meneruskan keluarga itu, sedangkan anak perempuan tidak demikian adanya. Karena sesuai dengan system kekeluargaan patrilineal (di Bali) anak perempuan akan keluar dari keluarganya dengan diadakannya perkawinan. Sistem kekeluargaan patrilinial ini merupakan ciri khas dalam hukum adat waris Bali dalam menentukan golongan ahli waris. Golongan ahli waris pertama adalah turunan pewaris kencang kebawah (decendenten) yaitu anak kandung atau anak sentana (Panetje, 2004).

Hukum waris adat di Bali memberlakukan sistem kekeluargaan (Dangin, 2015), dimana ditinjau berdasarkan sistem keturunannya adalah menganut sistem keturunan patrilineal (Hadikusuma, 1991). Sistem kewarisannya diatur dalam kitab Dharmacastra Atha Nawoo'dhayah (buku kesembilan) dimana setelah kematian seorang ayah atau ibu, saudara-saudara karena telah berkumpul dapat membagi-bagikan diantara sebanding yang sama dengan kekayaan orang tuanya ibunya karena tidak ada kekuasaan pada mereka atas harta itu selagi hidup orang tuanya Atau saudara laki-laki tertua sendiri dapat menguasai seluruh harta orang tuanya, sedangkan yang lain akan hidup di bawah asuhannya seperti hal selagi orangtuanya masih hidup.

Penelitian terdahulu tentang hak wanita tunggal terhadap warisan dalam hukum adat Bali mengemukakan bahwa keputusan Mahkamah Agung tanggal 10 April 1971 No. 770/K/ Sip/1970, yang pada pokoknya mengatakan bahwa harta peninggalan seorang suami masih belum dapat dibagi ahli warisnya selama almarhum belum diabenkan (Warsita, Suwitra, \& Sukadana, 2020). Sementara itu, menurut hukum adat waris yang berlaku pada masyarakat Hindu di Bali, janda bukan ahli waris dan tidak berhak mewaris atas harta peninggalan suaminya (Sutardjana, 2006) akan tetapi berhak menikmati hasil dari harta warisan (Yudiantara, 2013). Berdasarkan perspektif undang-undang perkawinan dan hukum adat Bali dalam penelitian lain mengatakan apabila terjadi perceraian suami-isteri berhak menguasai harta bawaan masing-masing dan harta yang mereka peroleh sebagai hadiah atau warisan. Sedangkan hak suamiisteri dalam pembagian harta bersama akan mendapatkan bagian sama rata (Puspayanthi \& Sudantra, 2017).

Secara umum, penelitian ini dilakukan untuk mengetahui kedudukan balu luh di Desa Adat Suter Bangli sesuai dengan peraturan perundang-undangan yang mengaturnya sedangkan secara khusus penelitian ini bertujuan untuk mengetahui kewajiban bagi krama balu luh di Desa Adat Suter Bangli dan kewenangan krama balu luh terhadap harta peninggalan suaminya.

\section{METODE PENELITIAN}

Lokasi penelitian yang diambil adalah di Desa Adat Suter Bangli terkait dengan kewajiban bagi krama balu luh dan kewenangan krama balu luh terhadap harta peninggalan suaminya, karena di desa adat Suter cukup banyak ada balu luh yang masih eksis menjalani kehidupan sampai sekarang. Penelitian hukum ini menggunakan metode penelitian hukum empiris. Menurut (Sunggono, 2003), penelitian hukum empiris adalah penelitian berupa studi-studi empiris untuk menemukan data-data mengenai proses terjadinya dan mengenai proses bekerjanya hukum di dalam masyarakat. Pendekatan masalah yang dipakai dalam penelitian ini adalah pendekatan sosiologi hukum. Pengumpulan data yang digunakan dalam penelitian ini adalah wawancara, studi dokumen dan observasi/pengamatan.

\section{HASIL DAN PEMBAHASAN} Kewajiban bagi Krama Balu Luh di Desa Adat Suter Bangli 
Krama desa dalam pergaulan hidup bermasyarakat berpedoman pada awigawig yang dibuat oleh krama desa sendiri. Awig-awig itu mengatur keserasian hubungan manusia dengan Sang Hyang Widi Wasa, hubungan manusia dengan sesama krama desa, dan hubungan manusia dengan alam (Sirtha, 2016). Di dalam Awig-Awig Desa Adat Suter sudah diatur masalah krama balu, hal ini dapat dilihat dari Sukerta Tata Pakraman, indik krama yang diatur dalam Pawos 5 ayat (3) antara lain:

Krama balu, kula warga ngarep utawi ngarep salah sinunggil rabi utawi istrine lina, wiadin nyapian:

Ha. Balu mekrambian, inggih punika balu sane maduwe sentane dereng merabian;

Na. balu ngelisting, inggih punika balu sane tanpa sentana.

Terjemahan bebasnya:

Warga balu, yaitu warga yang salah satu meninggal baik laki-laki maupun perempuan atau juga cerai:

a. Balu yang memiliki anak belum kawin.

b. Balu yang tidak memiliki anak.

Selanjutnya dalam kewajibannya juga diatur dalam $\operatorname{Pawos} 7$ sebagai berikut:

Tetegenan miwah swadharma Krama Desa Pakraman/Adat

Tetegenan krama, luwire:

Ha. Krama ngarep, keni urunan miwah ayahan mamungkul, Na. krama balu, keni ayah manut kawongania:

1. Balu ngelisting, lanang utawi istri keni ayahan lanang utawi istri

2. Balu makrambian, lanang utawi istri sane madruwe sentana lanang utawi istri sampung mayusa 17 (pitulas) warsa keni ayahan balu.

3. Balu nyapian, kedadosang luput pepeson sakewenten keni ayahan manut arah-arahan banjar/Desa Adat yening balu lanang ayah lanang, balu istri ayah istri.

Ca. krama pengele, keni ayah-ayahan sekadi mareresik ring Kahyangan Tiga, banjar lan tiosan manut ring kawigunan.

Terjemahan bebasnya:

Kewajiban warga antara lain:

a. Krama ngarep, kena iuran dan kewajiban membayar penuh;

b. Krama balu kena kewajiban sesuai keadannya:

1. Balu tidak punya anak, kena kewajiban hanya 1 orang laki-laki atau perempuan

2. Balu laki-laki atau perempuan (luh) yang memiliki anak yang berusia 17 (tujuh belas) tahun ada kewajiban membayar.

3. Balu nyapian (tidak memiliki anak) bisa luput atau tidak kena kewajiban membayar.

c. Krama tidak punya anak, tidak punya istri, kena kewajiban gotong royong di tempat-tempat sembahyang (Kahyangan Tiga) Pura Puseh, Pura Dalem dan Pura Desa.

Lebih lanjut Dalam Awig-Awig Desa Adat Suter juga ditekankan seorang janda predana yaitu yang dinyatakan dalam Pawos 42 sebagai berikut:

(1) Pawiwahan presida kawusang malarapan antuk palas merabian utawi kapademan.

(2) Wusan mapikuren riantukan salah sinunggil lina mapiteges balu, mekadi balu lanang utawi istri.

(3) Palas merabian inggih punika sangkaning mawiwit wicara.

(4) Sang ayat palas merabian patut atur supaksa palikitan riin sang rumawos 
(pengadilan Negeri) wastu tinas apadang pamutuse kabawos nyapian, wuku prajuru/dulu nyiriang kawentenannya ring desa saha keni pamelihn kulkul manut pararem. Terjemahan

(1) Perkawinan dianggap cerai disebabkan karena pisah atau karena kematian. (2) Perceraian dsebabkan salah satu meninggal disebut balu, baik balu laki-laki maupun balu perempuan (balu luh).

(3) Perceraian yaitu karena bermasalah.

(4) Yang disebut cerai harus dibuktikan dengan keputusan pengadilan, selanjutnya disiarkan oleh kelian banjar kepada krama banjar.

Dari Awig-awig tersebut di atas bahwa biasanya seorang janda harus melaksanakan kewajibannya atau yang disebut menjalankan darma-nya sebagai janda, dimana janda diberikan hak untuk menikmati harta peninggalan almarhum suaminya, tetapi tidak boleh menjual, menggadaikan dan memberikan kepada orang lain tanpa persetujuan dari keluarga almarhum suaminya jika anak- anaknya masih kecil.

Janda yang dikatakan tidak melaksanakan darma-nya dapat dilihat dalam Awig-awig Desa Adat Suter dalam Pawos 43 dibawah ini :

(1) Sang balu kabinayang dados:

ha. Balu luh wit sentana (sentana rajeg) miwah balu luh boya sentana;

na. Balu muani kapurusa (wit sentana) miwah balu muani nyeburin (boya sentana nyeburin).

(2) Swadarmaning balu inucap patut:

ha. Ngemangehang pati brata tan patut ngamargiang paradara/drati krama.

na. Nguwasayang waris gunakaya, tan dados ngadol, ngadeang, makidihang lan siosan puniki, sajawaning kabebasang sakeng pianak utawi kulawarga pinih tampek sakeng rabine prade okane kantun alit- alit.

ca. Kengin ngidih sentana prade wenten kecumpuin antuk kulawarga

sinanggeh kapurusa;

ra. Kewenangan mawiwaha malih yen wenten kabebasan manut aksara ring ajeng

(3) Balu kaucap tan pageh sekadi ring sor:

ha. Drati krama utawi paradara;

na. Matilar sakeng pakubon tan pasadok jantos 6 (enem) sasih;

ca. Lempas ring swadarma siwos-siwosan tan prasida ngesehin solah maprewerti marep ring pituduh kulawarga purusa.

Terjemahan:

(1) Ada dua jenis janda (balu) antara lain

a. Janda wanita (balu luh) berasal dari anak angkat dan anak sendiri. b. Duda (balu muani), yang berasal dari nyentana, atau duda sentana

(2) Kewajiban janda (balu luh) seperti:

a. Berprilaku tidak baik, wajib menyalurkan/berprilaku baik.

b. Tidak boleh mewaris, tidak boleh menjual warisan, menggadaikan, memberikan kepada orang lain dan lain-lain kecuali atas persetujuan anak-anak keluarga yang peling dekat dari almarhum suami jika anak- anak masih kecil.

c. Bisa mencari mantu atas persetujuan keluarga besar mantan suami (almarhum).

d. Bisa menikah lagi, jika sudah ada persetujuan anak-anak dan keluarga besar.

(3) Janda wanita (balu luh) tidak dibenarkan:

a. Membuat kerusuhan/masalah di keluarga.

b. Meninggalkan rumah tanpa pemberitahuan lebih dari 6 bulan.

c. Tidak bisa merubah sifat prilaku yang tidak baik terhadap keluarga almarhum. 
Berdasarkan wawancara penulis dengan Jro Wayan Alit, Bendesa Desa Adat Suter pada tanggal 15 Januari 2020 yang mengatakan bahwa: Janda tidak mewaris langsung dari harta peninggalan suaminya, namun janda berhak untuk menikmati harta warisan almarhum suaminya sepanjang janda tersebut tetap menjalankan darma-nya/kewajiban sebagai janda yaitu menegakkan kedisiplinan, taat melaksanakan kewajiban, melaksanakan upacara panca yadnya dan lain-lain, yang kemudian disebut dengan balu pageh, hak janda tersebut sepanjang hanya menikmatinya tidak bisa menjual, mengadaikan, dan memberikannya kepada orang lain kecuali atas persetujuan dari anak-anaknya dan keluarga almarhum suaminya jika anakanaknya masih kecil-kecil. Hal ini berlaku untuk harta pusaka dan harta guna kaya (harta perkawinan), karena untuk harta pusaka, janda tidak punya hak apapun, yang berhak ialah purusa dari keluarga almarhum suaminya, namun janda berhak untuk menikmatinya jika janda tersebut pageh.

Untuk harta perkawinan, yang diperoleh dari jerih payah keringat berdua antara janda tersebut dan almarhum suaminya, maka janda mendapat sebagian dan sebagian untuk anak-anaknya dan atau keluarga almarhum suaminya kalau perkawinan janda ini tidak ada keturunan. Janda yang masih berkumpul dengan anak-anaknya maka harta pembagian perkawinan itu menjadi hak anak-anaknya dan bukan saudara-sudara suaminya.

Untuk harta tetadan yaitu harta bawaan yang dibawa masuk dalam perkawinan oleh mempelai lakilaki atau perempuan, maka pada waktu menikah hal itu dibicarakan terlebih dahulu, apakah nanti setelah janda meninggal akan masuk keluarga asalnya atau keluarga suaminya.

Menurut I Wayan Winadi, Pangliman Desa Adat Suter wawancara pada tanggal 15 Januari 2020 mengatakan bahwa: "Dalam kebiasaan di Desa Adat Suter maka harta itu akan masuk ke keluargaa suaminya karena sudah dianggap kawin keluarga oleh keluarga asalnya namun dalam hal ini masih dalam pengawasan dari janda tersebut artinya jika janda tersebut meninggal semasih sebagai janda pageh maka akan diwarisi ke anak-anaknya atau keluarga suaminya, namun jika janda tersebut mulih daha maka harta ini akan ikut kembali keluarga asalnya".

Jadi dari uraian tersebut diatas, adapun kewajiban krama balu luh di Desa Adat Suter dilingkungan keluarga purusa akan tetap melaksanakan kewajiban seperti biasanya apabila balu luh tersebut masih tetap menjalankan dharmanya dalam artian tidak kawin lagi, balu luh tersebut katagori pageh yaitu dia tetap dapat tinggal di rumah manta suaminya (almarhum suaminya) sehingga mempunyai hak dan kewajiban sebagai balu luh pada umumnya.

\section{Kewenangan Krama Balu Luh terhadap Harta Peninggalan Suami}

Kewenangan balu luh sesuai dengan Awig-Awig Desa Adat Suter sebagai berikut:

1. Memelihara, membiayai dan kasih sayang terhadap anak.

2. Berwenang memelihara harta warisan dari suami (almarhum).

3. Berwenang untuk kawin lagi, tapi atas persetujuan anak dan keluarga almarhum.

4. Dapat meminta/mengangkat anak atas persetujuan keluarga.

Jadi dalam suasana adat Bali, janda sesungguhnya bukanlah orang yang harus ditelantarkan, dan bukan pula orang bisa diusir seenaknya. Tetapi sebagai janda yang menjalankan dharmanya sebagai janda akan selalu bertekun terhadap kewajibannya, memelihara anaknya, dengan baik, mengurusi kekayaan suami dengan baik, mengurusi pura keluarga dengan sepenuh hati, serta tidak menghamburkan kekayaan almarhum.

Janda yang mampu dan berusaha berbuat demikian adalah janda yang telah menjalankan kewajiban serta dharmanya sebagai janda, sehingga ia harus diperlakukan dengan baik oleh seluruh keluarga. Dalam batas-batas ini, janda adalah berhak sepenuhnya untuk menikmati kekayaan almarhum untuk kepentingan kelanjutan hidupnya. Sedang dalam hal tersebut untuk kepentingan keluarga dan almarhum maka janda juga berhak atas seijin keluarga terdekat untuk menjual harta yang ada untuk kepentingan keluarga seperti kepentingan pyra, pengabenan dan lain-lain.

Harta dalam keluarga yang diurus oleh si janda, dikehendaki agar dipergunakan untuk kepentingan kesejahteraan keluarga dalam arti kesejahteraan materiil dan immateriil. Dan jika janda sudah punya ulah yang lain yaitu menghamburkan kekayaan almarhum, kawin lagi, berzinah maka ia sudah keluar dari rel 
dharmanya sebagai janda sehingga keluarga berhak menegur untuk mengingatkan agar janda tidak berbuat demikian.

Tetapi jika tetap terus serakah maka janda berhak diusir karena telah berbuat bertentangan dengan "tugas sucinya" sebagai janda. Itu serentetan logika dan kenyataan adat yang ada di Bali. Dan kalau kita bandingkan dengan Putusan Pengadilan di Bali sejak dikeluarkan surat Edaran Mahkamah Agung di atas, logika hukum adat yang diwarisi sejak dulu ternyata tetap dilanjutkan.

Namun demikian yang perlu dipegang teguh dalam menggariskan kedudukan janda dalam putusanputusan tersebut terlihat syarat utama adalah jika anda masih menempati dharmanya sebagai janda. Jika ia kawin lagi tanpa persetujuan keluarga terdekat suami-isteri juga digolongkan telah keluar dari dharmanya sebagai janda. Sehingga dengan demikian prinsipnya janda adalah orang dibebankan kewajiban untuk mengurus harta peninggalan almarhum suaminya dengan baik untuk kepentingan dan tugas-tugas keluarga baik materiil/immateriil, serta untuk menghidupi dirinya dengan baik untuk bisa melaksanakan dharmanya sebagai janda.

Terkait dngan kewajiban dan hak balu luh tersebut diatas, Bapak Jro Wayan Alit Bendesa Desa Adat Suter, wawancara tanggal 15 Januari 2020 menegaskan bahwa Balu luh di Desa Adat Suter mempunyai kewenangan antara lain: memelihara keutuhan keluarga tidak berbuat yang tidak baik terhadap keluarga, tidak boleh menjual waris/gunakaya, menggadaikan, memberikan kepada orang lain, boleh minta anak/sentana tetapi atas persetujuan keluarga besar, dan boleh kawin lagi tapi atas persetujuan keluarga besar almarhum suami. Ini sesuai dengan Awig- Awig Desa Adat Suter Pawos 45.

Atas dasar pembahasan dan wawancara tersebut diatas, dapat dikatakan bahwa, balu luh di Desa Adat Suter memiliki kewenangan antara lain:

1. Memelihara keutuhan keluarga, tidak berbuat hal-hal yang tidak baik, sehingga dapat disebut balu luh yang pageh.

2. Tidak berberwenang menjual, memindahtangankan harta yang ditinggalkan oleh almarhum suaminya.

3. Boleh meminta anak/sentana, tapi atas persetujuan keluarga besar almarhum suami.

4. Juga boleh kawin lagi atas persetujuan keluarga besar almarhum suami.

\section{SIMPULAN DAN SARAN}

\section{Simpulan}

Berdasarkan uraian diatas dapatlah ditarik simpulan sebagai berikut:

1. Kewajiban bagi krama balu luh di Desa Adat Suter Bangli antara lain mengurus harta peninggalan almarhum suaminya dengan baik, berperilaku baik, menegakkan kedisiplinan, taat melaksanakan kewajiban, melaksanakan upacara panca yadnya dan lainlain, yang kemudian disebut dengan balu pageh, hak janda tersebut sepanjang hanya menikmatinya tidak bisa menjual, mengadaikan, dan memberikannya kepada orang lain kecuali atas persetujuan dari anak-anaknya dan keluarga almarhum suaminya jika anakanaknya masih kecil-kecil. Hal ini berlaku untuk harta pusaka dan harta guna kaya (harta perkawinan), karena untuk harta pusaka, janda tidak punya hak apapun, yang berhak ialah purusa dari keluarga almarhum suaminya, namun janda berhak untuk menikmatinya jika janda tersebut pageh.

2. Kewenangan krama balu luh terhadap harta peninggalan suaminya antara lain:

a. Memelihara keutuhan keluarga, tidak berbuat hal-hal yang tidak baik, sehingga dapat disebut balu luh yang pageh.

b. Tidak berberwenang menjual, memindahtangankan harta yang ditinggalkan oleh almarhum suaminya.

c. Boleh meminta anak/sentana, tapi atas persetujuan keluarga besar almarhum suami. 
2. Saran

d. Juga boleh kawin lagi atas persetujuan keluarga besar almarhum suami.

Sesuai dengan simpulan tersebut diatas, dapat penulis sampaikan saran sebagai berikut:

1. Kedudukan balu luh dalam hukum adat waris Bali belum memenuhi rasa keadilan padahal sesuai perkembangan zaman dewasa ini seorang wanita mempunyai kesempatan yang sama dalam meraih karir yang diinginkan seperti contoh merawat/memelihara rumah tangga, mengurusi keluarga jika suaminya bekerja. Dengan demikian hendaknya hak dan kewajiban baik balu luh maupun duda agar disamakan termasuk dalam hak-hak mewaris, ini hendaknya diatur didalam Awig-Awig atau Pararem.

2. Apabila seorang janda ingin kembali kerumah asalnya, diharapkan melalui jalan mulih daha, karena jika tidak status janda ini akan ngambang, tidak menjadi bagian keluarga dirumah almarhum suaminya juga tidak menjadi bagian keluarga asalnya. Dengan demikian diharapkan apabila balu luh telah melaksanakan kewajiban yang baik dan benar yang disebut ajeg dapat diberikan untuk tetap di rumah suaminya alias mulih daha ke rumah asal atau jangan terlalu dibebani kewajiban lagi sesuai adat. Dalam hal ini adat yang harus menyesuaikan dengan perkembangan zaman dewasa ini.

\section{DAFTAR PUSTAKA}

Dangin, N. L. G. I. P. (2015). Kedudukan Hak Mewaris Wanita Hindu dalam Sistem Hukum Adat Waris di Bali. Jurnal Hukum. from http://hukum.studentjournal.ub.ac.id/index.php/hukum/article/view/842

Hadikusum, H. (2003). Hukum Waris Adat. Bandung: PT. Citra Aditya Bakti.

Hadikusuma, H. (1991). Hukum Waris Indonesia menurut Perundang-undangan, Hukum Adat, Hukum Hindu, Islam. Bandung: PT. Citra Bakti.

Harum, I. G. P. M., \& Kusuma, A. A. G. A. D. (2013). Kedudukan Ahli Waris Perempuan Bali dalam Perspektif Hukum Waris di Indonesia. Kertha Semaya, 1(6). Retrieved from https://ojs.unud.ac.id/index.php/kerthasemaya/article/view/6277

Panetje, G. (2004). Aneka Catatan Tentang Hukum Adat Bali. CV. Kayumas.

Puspayanthi, L. P. D., \& Sudantra, I. K. (2017). Kedudukan Suami Istri terhadap Harta Benda Perkawinan dalam Hal Terjadi Perceraian: Perspektif Undang-Undang Perkawinan dan Hukum Adat Bali, 4(2). Retrieved https://ojs.unud.ac.id/index.php/kerthadesa/article/view/35336?articlesBySameAuthorPage=3

Sirtha, I. N. (2016). Desa Pakraman. Universitas Udayana. Retrieved from https://simdos.unud.ac.id/uploads/file_penelitian_1_dir/3898a0594dc1da5de82c83289cbef1ad.pdf

Sunggono, B. (2003). Metode Penelitian Hukum. Jakarta: PT Raja Grafindo Persada.

Sutardjana, I. K. G. (2006). Kedudukan Janda terhadap Harta Peninggalan Suami Menurut Hukum Waris Adat Bali. Universitas Airlangga. Retrieved from http://repository.unair.ac.id/36230/

Sutha, I. G. K. (1982). Beberapa Aspek Hukum Waris Bali. Majalah Kertha Patrika. Universitas Udayana.

Suwitra, I. M. (2014). Eksistensi Hak Penguasaan dan Pemilikan Atas Tanah Adat di Bali. Bandung: Logos Publishing.

Warsita, I. P. A., Suwitra, I. M., \& Sukadana, I. K. (2020). Hak Wanita Tunggal terhadap Warisan dalam Hukum Adat Bali. Jurnal Analogi Hukum, 2(1). Retrieved from https://www.ejournal.warmadewa.ac.id/index.php/analogihukum/article/view/1628

Yudiantara, I. G. E. J. (2013). Kedudukan Wanita Balu Dalam Hukum Adat Bali (Studi Kasus Implementasi Nilai Harmonisasi dalam Hak dan Kewajiban Wanita Balu Di Desa Belega, Kecamatan Blahbatuh, Kabupaten Gianyar). Jurnal Pendidikan Kewarganegaraan UNDIKSHA, 1(2). Retrieved from https://ejournal.undiksha.ac.id/index.php/JJPP/article/view/408

Yusa, I. G. (2017). Hak Pewarisan Nyentana Di Desa Adat Panglipuran Kubu Kabupaten Bangli. E-Journal 
Jurnal Preferensi Hukum

Vol. 1 No. 12020

Ilmu Hukum Kertha Desa, 4(2). Retrieved from https://ojs.unud.ac.id/index.php/kerthadesa/article/view/39506?articlesBySameAuthorPage=3 